\title{
A high-resolution free-surface model of the Mediterranean Sea
}

\author{
M. Tonani ${ }^{1}$, N. Pinardi ${ }^{2}$, S. Dobricic ${ }^{3}$, I. Pujol ${ }^{1}$, and C. Fratianni ${ }^{1}$ \\ ${ }^{1}$ Istituto Nazionale di Geofisica e Vulcanologia, Bologna, Italy \\ ${ }^{2}$ University of Bologna, Corso di Scienze Ambientali, Ravenna, Italy \\ ${ }^{3}$ Centro Euro-Mediterraneo per i Cambiamenti Climatici, Bologna, Italy
}

Received: 8 January 2007 - Published in Ocean Sci. Discuss.: 26 February 2007

Revised: 16 November 2007 - Accepted: 13 December 2007 - Published: 24 January 2008

\begin{abstract}
This study describes a new model implementation for the Mediterranean Sea with what is currently the highest vertical resolution over the Mediterranean basin. The resolution is of $1 / 16^{\circ} \times 1 / 16^{\circ}$ in the horizontal and has 72 unevenly spaced vertical levels. This model has been developed in the frame of the EU-MFSTEP project and is the operational forecast model currently used at the basin scale.

The model considers an implicit free surface and this characteristic enhances the model's capability to simulate the sea surface height variability and the net transport at the Strait of Gibraltar.

In this study we show the calibration/validation experiments performed before and after the model was used for forecasting. The first experiment consists of a six-year simulation forced by a perpetual year forcing, and the other experiment is a simulation from January 1997 to December 2004, forcing the model with 6-h atmospheric forcing fields from ECMWF. The model Sea Level Anomaly has been compared for the first time with satellite SLA and with ARGO data to provide evidence of the quality of the simulation.

The results show that this model is capable of reproducing most of the variability of the general circulation in the Mediterranean Sea. However, some basic model inadequacies stand out and should be corrected in the near future.
\end{abstract}

\section{Introduction}

The aim of this study is to give a detailed description of the Mediterranean Sea forecasting model implementation studies performed during the MFSTEP project in order to assess the quality of the numerical model that is now used for the daily forecasts at the basin scales.

Correspondence to: $\mathrm{M}$. Tonani

(tonani@bo.ingv.it)
The first model used for forecasting at the basin scale has been described by Pinardi et al. (2003). The previous implementation consisted of a version of the Modular Ocean Model $(\mathrm{MOM})$ with a $1 / 8^{\circ} \times 1 / 8^{\circ}$ horizontal resolution and 31 levels in the vertical. The present model is a version of the Océan PArallélisé (OPA) code (Madec et al., 1998) and its horizontal and vertical resolution is the highest presently available for the Mediterranean Sea: $1 / 16^{\circ} \times 1 / 16^{\circ}$ degrees in the horizontal (approx. $6.5 \mathrm{~km}$ ) and 72 vertical levels. The level of depths are unevenly spaced and have a thickness ranging from $3 \mathrm{~m}$ at the surface to $300 \mathrm{~m}$ at the ocean bottom. The depth of the first level is $1.5 \mathrm{~m}$ and that of the deepest is $5000 \mathrm{~m}$. The model could be therefore defined as a mesoscale-resolving model for the Mediterranean Sea, since the first internal Rossby radius of deformation is around 10$15 \mathrm{~km}$ in summer and for most of the Mediterranean subregional seas (with the exception of the Adriatic Sea). Figure 1 shows a comparison between the vertical resolution of a CTD salinity profile by the 72-level (panel a) and 31-level models (panel b). The continuous line is the CTD profile from the bottom down to $300 \mathrm{~m}$ and the dots are the positions of the vertical levels of the model. It is clear that when there are only few levels (panel b), all the small scales are missed and, moreover, the depth of the sub-superficial minimum is displaced. Several of these comparisons between data and model level distribution were performed in a preliminary phase in order to decide the number of levels of the vertical grid of the model. The model is also new for the Mediterranean Sea since it uses an implicit free-surface parameterization instead of a rigid lid like all the other models implemented for the region (Demirov and Pinardi, 2002; Beranger et al., 2004).This allows for a water flux forcing in equilibrium with the salt flux. Furthermore, free-surface models in the Mediterranean Sea allow an important improvement in the realism of the simulations permitting a net water influx at Gibraltar to compensate for the positive water losses at the air-sea interface. Rigid lid models cannot

Published by Copernicus Publications on behalf of the European Geosciences Union. 

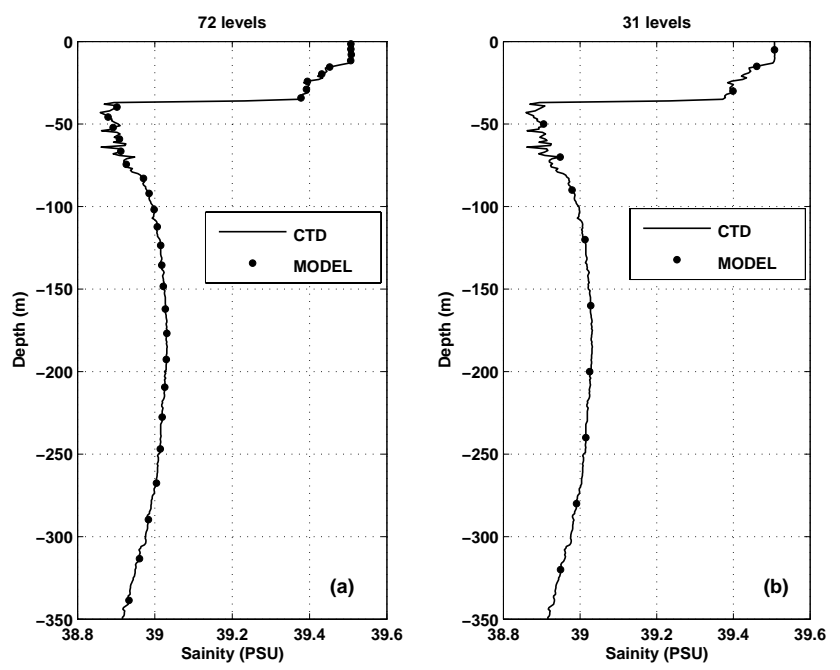

Fig. 1. Salinity profile from CTD in the eastern Mediterranean and its discretisazion by the model levels for the case of 72 levels (panel a) and 31 levels (panel b). The full line is the CTD profiles and the dots represents the depths of the model vertical levels.

in fact have a net transport at Gibraltar, and this is a feature missing from all previous high-resolution simulations. Figure 2 shows a comparison between the dynamic topography (panel a) and the steric component (panel b) between the rigid lid $1 / 8^{\circ} \times 1 / 8^{\circ}$ horizontal resolution model and the free-surface $1 / 16^{\circ} \times 1 / 16^{\circ}$ model. The comparison was made for 1999. The low-resolution rigid lid model is not able to simulate the seasonal variability of the dynamic topography well, and has a really smooth shape with respect to the freesurface and high-resolution model. The dynamic topography has been computed from the sea surface pressure for the rigid lid model and from the sea surface high for the free-surface one. Panel b) shows the variability of the sea level high due to the steric effect. We have computed this variabillity from the climatological data of MEDATLAS (MEDAR/MEDATLAS Group 2002) and from the two model simulations. It is clear from Fig. 2 that the low resolution model has a higher variability, which could be due to the low vertical resolution of the model that is not adequate to represent the seasonal variability of the characteristics of the water column. The highresolution model, on the contrary, has a variability much closer to the steric component of the climatology; it therefore seems to be more efficient in the simulation of the water column property variability due to the seasonal variability.

This paper is organized in the following way: Sect. 2 gives a detailed description of the model equations and parameter choices; Sect. 3 describes the experimental design; Sect. 4 describes the simulation results and the comparison with the observations; Sect. 5 offers the conclusions.

\section{Model equations and parameter choices}

\subsection{Model equations and domain of implementation}

The model uses the primitive equations with the Boussinesq and incompressible approximations written in spherical coordinates $(\lambda, \varphi, z)$, where $\varphi$ is the latitude, $\lambda$ the longitude and $z$ the depth. The set analytical expressions for the equations are:

$$
\begin{aligned}
\frac{\partial u}{\partial t} & =(\zeta+f) v-w \frac{\partial u}{\partial z}-\frac{1}{2 a \cos \varphi} \frac{\partial}{\partial \lambda}\left(u^{2}+v^{2}\right) \\
& -\frac{1}{\rho_{0} a \cos \varphi} \frac{\partial p}{\partial \lambda}-A^{l m} \nabla^{4} u+\frac{\partial}{\partial z}\left(A^{v m} \frac{\partial u}{\partial z}\right) \\
\frac{\partial v}{\partial t} & =-(\zeta+f) u-w \frac{\partial v}{\partial z}-\frac{1}{2 a} \frac{\partial}{\partial \varphi}\left(u^{2}+v^{2}\right) \\
& -\frac{1}{\rho_{0} a} \frac{\partial p}{\partial \varphi}-A^{l m} \nabla^{4} v+\frac{\partial}{\partial z}\left(A^{v m} \frac{\partial v}{\partial z}\right) \\
\frac{\partial p}{\partial z} & =-\rho g
\end{aligned}
$$

$\frac{1}{\alpha \cos \varphi}\left(\frac{\partial u}{\partial \lambda}+\frac{\partial}{\partial \varphi}[\cos \varphi v]\right)+\frac{\partial w}{\partial z}=0$

$$
\begin{aligned}
& \frac{\partial \theta}{\partial t}=-\frac{1}{a \cos \varphi}\left[\frac{\partial}{\partial \lambda}(\theta u)+\frac{\partial}{\partial \varphi}(\cos \varphi \theta v)\right]-\frac{\partial}{\partial z}(\theta w) \\
& -A^{l T} \nabla^{4} T+A^{v T} \frac{\partial^{2} \theta}{\partial z^{2}}+\delta \mu\left(\theta^{*}-\theta\right) \\
& \frac{\partial S}{\partial t}=-\frac{1}{\alpha \cos \varphi}\left[\frac{\partial}{\partial \lambda}(S u)+\frac{\partial}{\partial \varphi}(\cos \varphi S v)\right]-\frac{\partial}{\partial z}(S w) \\
& -A^{1 S} \nabla^{4} S+A^{v S} \frac{\partial^{2} S}{\partial z^{2}}+\delta \mu\left(S^{*}-S\right) \\
& \rho=\rho(T, S, p)
\end{aligned}
$$

where we recognize that the momentum equations have been re-written in their vorticity form (Pedlosky 1983). In Eqs. (1) to (7), $u, v, w$ are the components of the velocity vector; $\varsigma=\frac{1}{a \cos \varphi}\left(\frac{\partial v}{\partial \lambda}-\frac{\partial}{\partial \varphi}[u \cos \varphi]\right)$ is the vorticity; $a$ the earth radius; $f=2 \Omega \sin \varphi$ the Coriolis term with $\Omega$ the constant earth rotation rate; $p$ the hydrostatic pressure; $\theta$ the potential temperature, $S$ the salinity, $\rho$ the in situ density and $\rho_{o}=1020 \mathrm{~kg} / \mathrm{m}^{3}$ the reference density; $A^{l m}, A^{v m}$ the horizontal and vertical eddy viscosities; $A^{v T}, A^{v S}$ the vertical diffusivities; $A^{l T}, A^{l S}$ the horizontal diffusivities; $\delta$ and $\mu$ are the relaxation coefficients, which will be described in details later.

The numerical model code that discretizes Eqs. (1) to (7) is OPA (Océan PArallélisé) version 8.2 described in Madec et al. (1998). Here we use the OPA version with the implicit free surface so that the latter, denoted by $\eta$, is a prognostic 

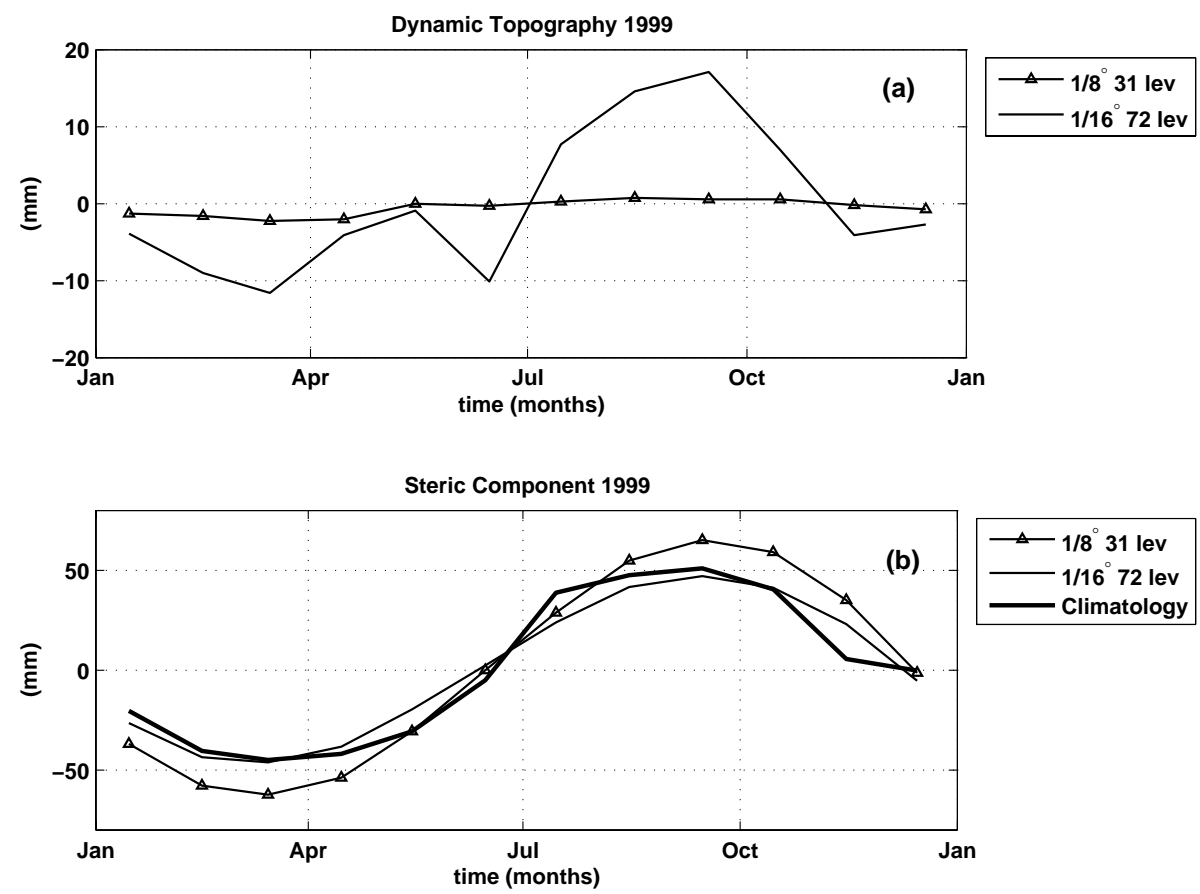

Fig. 2. comparison between the rigid lid low resolution model and the free-surface high-resolution one. Panel (a) shows the mean dynamic topography $(\mathrm{mm})$ for 1999 computed from the two models respectively as sea surface high or pressure minus the mean over all of 1999 . The line with triangles is the dynamic topography from the low-resolution model whilst the continuous line is the high-resolution model. The values are computed as monthly means and are mean over the whole Mediterranean basin. Panel (b) show the comparison of the steric component $(\mathrm{mm})$ computed from the temperature and salinity fields of the two models (line with triangles for the low-resolution model) and from the monthly mean climatology MEDATLAS (thick line).

variable. The numerical scheme for the free surface is described by Roullet et al. (2000).

The model domain and the bathymetry are shown in Fig. 3: the coastline resolves 49 islands. The procedure used to make the coastline, the bathymetry and the vertical level distribution is described in the Appendix. The Atlantic box is very large with respect to previous implementations (Demirov and Pinardi, 2002) and it will be described in detail below.

\subsection{Sub-grid-scale parameterizations}

The horizontal eddy viscosity $\left(A^{l m}\right)$ is considered to be a constant value of $5 \times 10^{9} \mathrm{~m}^{4} / \mathrm{s}$ whilst the horizontal diffusivities $\left(A^{l T}, A^{l S}\right)$ are equal and set to the value of $3 \times 10^{9} \mathrm{~m}^{4} / \mathrm{s}$. The vertical diffusivities $\left(A^{v S}, A^{v T}\right)$ and viscosity $\left(A^{v m}\right)$ are a function of the Richardson number as parametrized by Pakanowsky and Philander-PP (1981), i.e.:

$A^{v T}=\frac{100 \times 10^{-4}}{\left(1+5\left(N^{2} /\left(\partial \mathbf{U}_{h} / \partial z\right)^{2}\right)\right)^{2}}+\left(1.5 \times 10^{-4}\right)$

$A^{v m}=\frac{A^{v T}}{1+5\left(N^{2} /\left(\partial \mathbf{U}_{h} / \partial z\right)^{2}\right)}+\left(3 \times 10^{-4}\right)$

where the vertical salinity diffusivity is equal to Eq. (8). The PP parameterization is thought to be relevant for mixed-layer processes whilst deep convection needs another parametrization. The model thus uses enhanced vertical diffusion to produce deep convection: the vertical diffusivity and viscosity coefficients are assigned to be equal to $1 \mathrm{~m}^{2} / \mathrm{s}$ in regions where the stratification is unstable.

\subsection{Vertical boundary conditions}

At the bottom, $z=-H(x, y)$, we impose:

a) for the vertical velocity:

$$
w=-\boldsymbol{u}_{h}^{b} \cdot \nabla H
$$

where $\boldsymbol{u}_{h}^{b}=\left(u_{b}, v_{b}\right)$ is the bottom velocity assumed to be the deepest layer velocity;

b) for the momentum, temperature and salt flux:

$$
\begin{aligned}
& \left.A^{v m} \frac{\partial}{\partial z}\left(\boldsymbol{u}_{h}\right)\right|_{z=-H}=C_{D} \sqrt{u_{b}^{2}+v_{b}^{2}+e_{b} \boldsymbol{u}_{h}^{b}} \\
& \left.A^{v T} \frac{\partial}{\partial z}(T, S)\right|_{z=-H}=0
\end{aligned}
$$

where $C_{D}=10^{-3}$ is the drag coefficient and $e_{b}$ is the bottom eddy kinetic energy due to the tides, internal 


\section{MODEL TOPOGRAPHY}

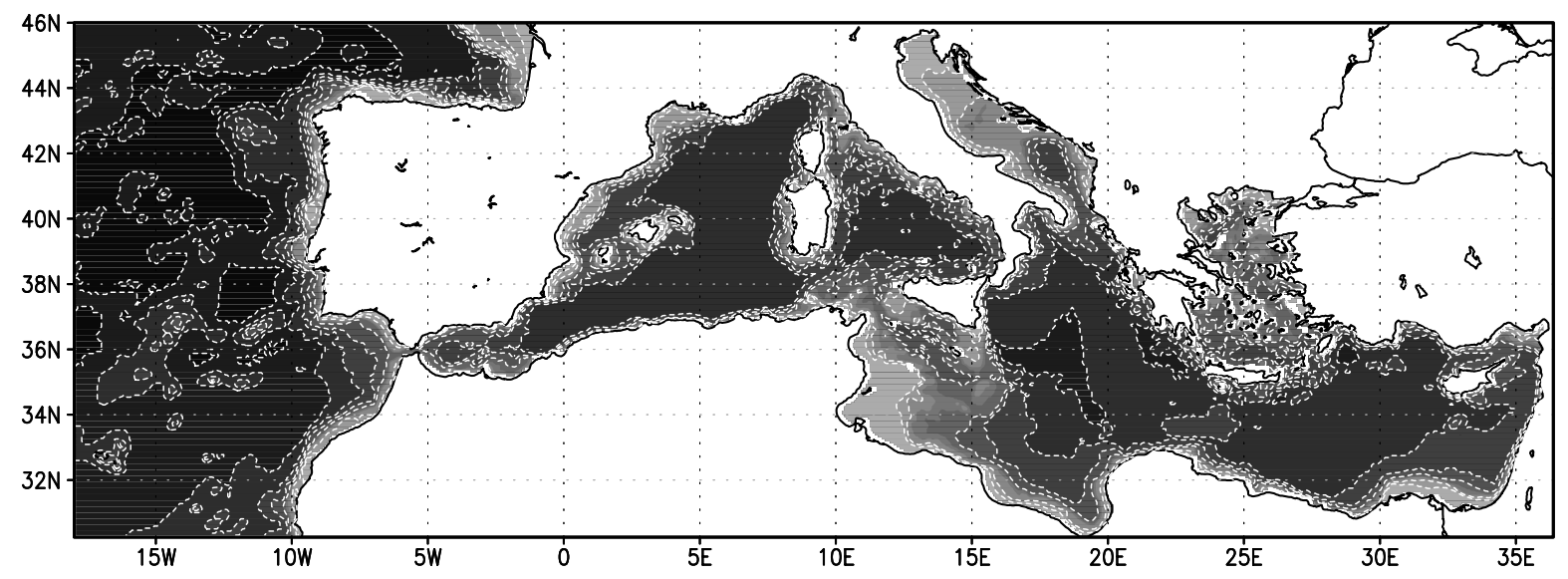

$$
\begin{array}{llllllllll}
-5000 & -3500 & -2000 & -1000 & -500 & -300 & -200 & -100 & -50 & 0
\end{array}
$$

Fig. 3. Model bathymetry and domain.

waves breaking, and to all the other contributions at very short spatial and temporal scales.

At the surface, $z=\eta$, the boundary conditions are:

a) for the vertical velocity

$w=\frac{D \eta}{D t}-(E-P)$

where $\frac{D \eta}{D t}=\frac{\partial \eta}{\partial t}+\boldsymbol{u}_{h} \cdot \nabla \eta P$ is the precipitation and $E$ the evaporation $(E)$. This is the so-called water flux boundary condition.

b) The momentum boundary condition is:

$\left.A^{v m} \frac{\partial \boldsymbol{u}_{h}}{\partial z}\right|_{z=n}=\frac{\left(\tau_{u}, \tau_{v}\right)}{\rho_{0}}$

where $\tau_{u}, \tau_{v}$ are the zonal and meridional wind stress components respectively.

c) The heat flux boundary condition is:

$\left.A^{v T} \frac{\partial T}{\partial z}\right|_{z=0}=\frac{Q}{\rho_{0} C_{p}}$

where $C_{p}=4000 \mathrm{~J} /\left(\mathrm{kg}^{\circ} \mathrm{K}\right)$ and $Q\left(\mathrm{~W} / \mathrm{m}^{2}\right)$ is the nonpenetrative net heat flux at the surface. In our case, all the heat is assumed to be absorbed at the surface.

d) The boundary condition for the salinity is:

$\left.\rho_{0} A^{v S} \frac{\partial S}{\partial z}\right|_{z=0}=(E-P) S \rho_{0}$ where $S$ is the surface salinity which corresponds to the water flux condition, Eq. (13).

The water flux has been chosen as:

$\rho_{0}(E-P)=\gamma^{-1} \frac{\left(S-S^{*}\right)}{S}$

where $S$ is the model surface salinity, $S^{*}$ is the climatological surface salinity and $\gamma=-0.007\left(\mathrm{~m}^{2} \mathrm{~s} / \mathrm{kg}\right)$ is the salinity relaxation coefficient. The corresponding relaxation time is:

$$
\begin{aligned}
& \frac{1}{\rho_{0}} \gamma^{-1} \frac{\left(S-S^{*}\right.}{S}=\frac{\Delta z}{\Delta t} \\
& \Delta t=\rho_{0} \Delta z \gamma\left(\frac{S}{S-S^{*}}\right)
\end{aligned}
$$

If $\Delta z=3 \mathrm{~m}$ is the first model layer depth, $\Delta t \cong 5$ days.

\subsection{The Atlantic box and the Strait of Gibraltar}

The model domain shown in Fig. 3 extends into the Atlantic, and this part is called the Atlantic box. This box is necessary in order to simulate the exchange of water masses at the Gibraltar Strait properly. The latter therefore considers relaxation to climatology and vanishing currents at the last boundary point. The model salinity and temperature fields along a strip at the latitudinal and longitudinal boundaries of the Atlantic box (Fig. 3) are relaxed at all depths to the climatology with the terms introduced in Eqs. (5) and (6). The strip is an area with an extension of $2^{\circ}$ at the westward and 
southward boundaries and $3^{\circ}$ at the northern boundary (in order to cover all the area of the Gulf of Biscay).

The $\mu$ coefficient varies spatially, whilst $\delta$ is a time factor: $\mu$ is larger closer to the boundary points of the box and linearly decreases to zero outside the strip and $\delta=2.3 \times 10^{-7} \mathrm{~s}^{-1}$. The horizontal diffusivities are also incremented by a factor of 5 in the Atlantic box strip areas in order to add a sponge layer.

Some modifications are necessary at the Strait of Gibraltar to avoid unrealistic values of the transport at this strait. The horizontal viscosity is laplacian in the region between $6.25^{\circ} \mathrm{W}$ and $5.125^{\circ} \mathrm{W}$, whilst in the rest of the basin it is bilaplacian. The diffusivity in this area is 10 times larger than in the rest of the model. In the same geographical area the bottom friction drag coefficient is linear and ten times larger then in the other parts of the model. Out of the Strait of Gibraltar in the Atlantic Box, the bathymetry has been modified in order to resolve the Camarinam Sill (Sannino et al., 2004).

\subsection{The water flux correction}

The domain of Fig. 3 has closed boundaries and care should be taken in considering the effects of net sources/sinks of heat and water in the basin. In the Atlantic box, heat and salt is added or substracted by the relaxation terms in Eqs. (5) and (6), which are different from zero along the strip of the lateral boundaries, as described above. These terms will balance the heat loss and the salt gain from the sea surface, over the Mediterranean part of the basin in particular.

However, care should be taken for the surface water boundary condition - Eq. (13) - which sets the sea surface height of the basin and therefore the mass conservation. We develop here a way to correct the water balance in a closed model domain that conserves mass under the conditions of negative surface net water flux. It is well known that the Mediterranean basin on a yearly average has a net water loss due to $E$ exceeding $P$. The water lost at the surface of the Mediterranean Sea is balanced by a net inflow of water at the Gibraltar Strait. We need to enforce this balance so that the model volume does not drift.

The basin mean $(E-P)$ is then separated into two components, the Atlantic and Mediterranean:

$E-P=(E-P)_{\mathrm{MED}}+(E-P)_{\mathrm{ATL}}$

At each time step, the space integral of the Mediterranean and Atlantic water flux is computed and the sum of this two components of the water flux, $\Delta_{E-P}$, is computed:

$\int_{x, y}(E-P)_{\mathrm{MED}}+\int_{x, y}(E-P)_{\mathrm{ATL}}=\Delta_{E-P}$

$\Delta_{E-P}$ will be now used to compute a new value for the water flux over the Atlantic in order to have the net water flux equal zero over the whole domain. This does not change the Mediterranean basin water loss, but it balances it so that

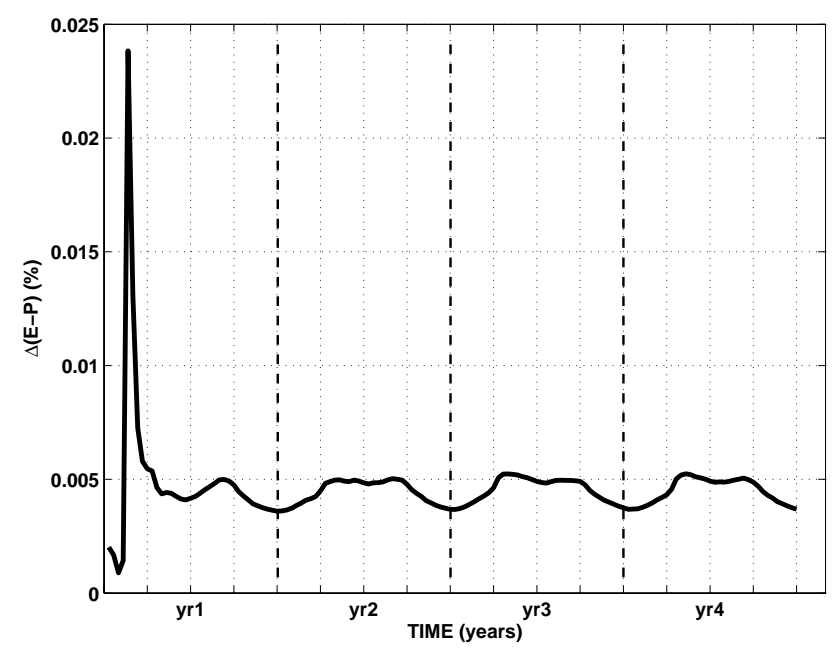

Fig. 4. Water flux correction factor, $\Delta(E-P)$, over all the Atlantic box computed for the first five years of the perpetual year simulation. The value of $\Delta(E-P)$ is computed as the percentage of the total water flux value in the Atlantic Box.

mass is conserved. A value of $(E-P)_{\text {ATL_CORR }}$ is therefore recomputed for each Atlantic grid point in the following way:

$(E-P)_{\mathrm{ATL}_{-} \mathrm{CORR}}=\Delta_{E-P} / \mathrm{AREA}_{\mathrm{ATL}}-(E-P)_{\mathrm{ATL}}$

where AREA $_{\mathrm{ATL}}$ is the Atlantic surface area. This assumption can be made only if the model is not used for climate simulations that cover hundreds of years, a period over which the modification of the water flux into the Atlantic box may be relevant and non-negligible. Figure 4 shows the value of $\Delta_{E-P}$ computed as percentage of the $(E-P)_{\text {ATL_CORR }}$ in one of the experiments studied in this paper. This value after the first months of simulation decreases and assumes a value of ca. $0.005 \%$. This value is small enough, and moreover does not increase during the simulation. Therefore we argue that this approximation, is valid for short term forecasting purposes.

\subsection{Design of the numerical experiments}

The model described in Sect. 2 was run with two different approximations of the atmospheric forcing:

1) the so-called perpetual year forcing, where the water, heat and momentum surface fluxes are monthly varying climatological mean values;

2) with 6-h meteorological forcing for the period January 1997 to December 2004.

In the following we describe the model design for each of these experiments. 

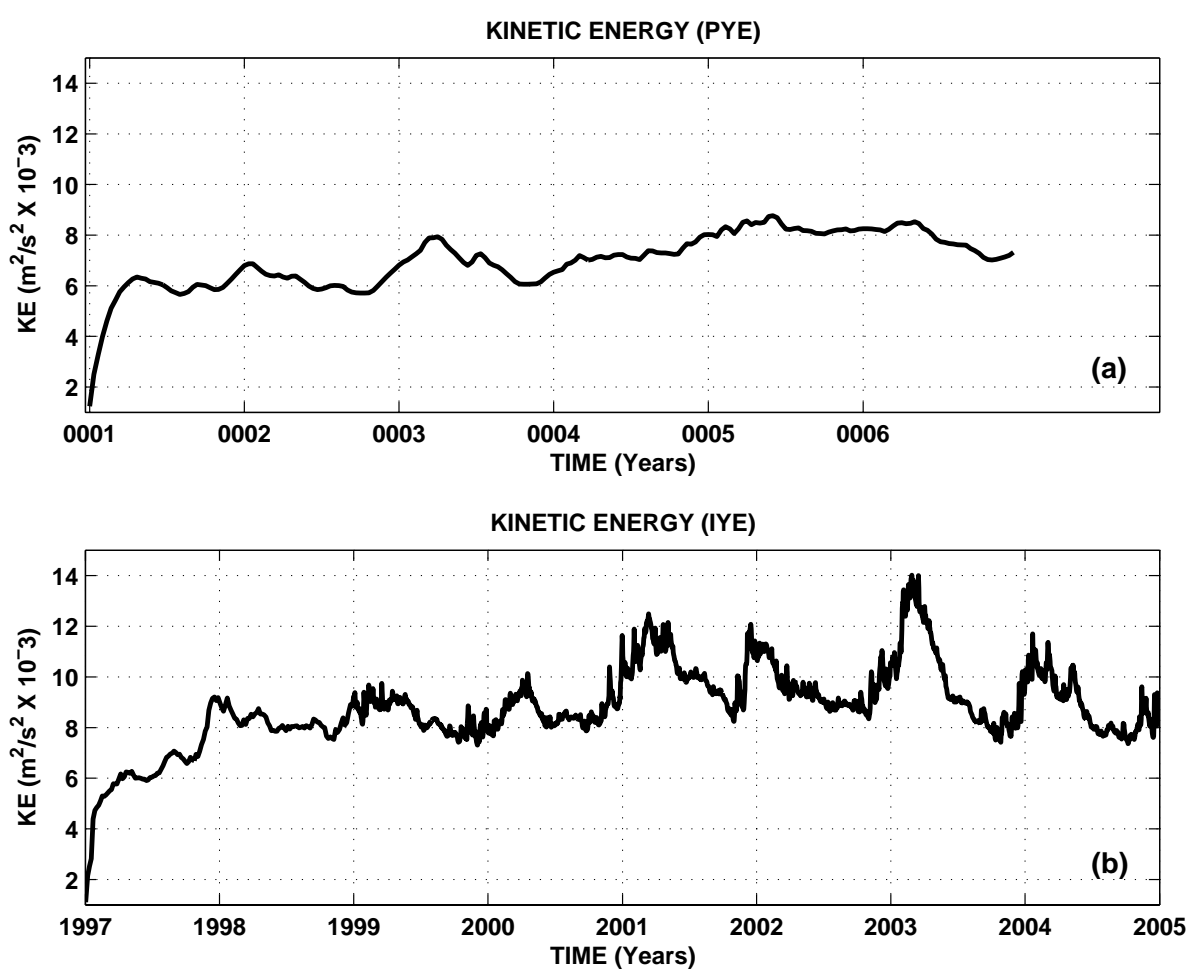

Fig. 5. Volume integral of the kinetic energy $\left(\mathrm{m}^{2} / \mathrm{s}^{2} \times 10^{-3}\right)$ computed for the six years of the experiment with the perpetual year forcing with a time period averaging ten days (panel a) and for the eight years with interannual atmospheric forcing with a time period averaging one day (panel b).

\subsection{Perpetual year experiment (PYE)}

The perpetual year experiment, hereafter called PYE, considers seasonally repeating heat, water and momentum fluxes at the sea surface. The model was initialized with a salinity and temperature field from the January monthly mean of MEDATLAS climatology (MEDAR/MEDATLAS Group 2002) and with zero velocity field. A detailed description of the wind stress climatology, composed of monthly mean wind stresses previously computed, is given in the Appendix. This wind stress climatology is used in Eq. (14).

In the perpetual year simulation, $Q$ in Eq. (15) is defined as:

$Q=Q_{0}+\frac{d Q}{d T}\left(T-T^{*}\right)$

where $Q_{0}$ is the net heat flux from the monthly mean climatology (described in the Appendix), $T$ is the model surface temperature, $T^{*}$ is the climatological surface temperature (see Appendix) and $d Q / d T=-40\left(\mathrm{~W} / \mathrm{m}^{2}{ }^{\circ} \mathrm{K}^{-1}\right)$ is the relaxation coefficient. The heat flux relaxation time $\Delta \tau$ corresponding to the relaxation factor is:

$\frac{d Q / d T}{\rho_{0} C_{p}}=\frac{\Delta z}{\Delta \tau} \quad \Delta \tau=\Delta z \frac{\rho_{0} C_{p}}{d Q / d T}$

Since the model surface layer thickness is $\Delta z=3 \mathrm{~m}$, then $\Delta \tau \cong 3,5$ days.

\subsection{Interannual forcing experiment (IYE)}

In the interactive physics experiments, hereafter called IYE, the wind stress for Eq. (14) is calculated interactively starting from 6-h surface meteorological fields from ECMWF using bulk formulas.

For the wind stress the surface winds are transformed in stress using the Hellerman and Rosenstein (1983) bulk parameterization and are used in Eq. (14).

For the heat flux in Eq. (15) we use:

$$
\begin{aligned}
& Q=Q_{S}-Q_{B}\left(T_{a}, T_{0}, C, r h\right)-L E\left(T_{a}, T_{0}, r h,\left|\boldsymbol{V}_{W}\right|\right) \\
& \quad-H\left(T_{a}, T_{0},\left|\boldsymbol{V}_{w}\right|\right)
\end{aligned}
$$

where the terms on the right-hand site are: the net short wave incoming radiation, $Q_{s}$; the net long wave re-emitted by the surface, $Q_{B}$; the latent, $L E$, and the sensible heat flux, $H$. They depend upon the air temperature at $2 \mathrm{~m}, T_{a}$; the sea surface temperature computed by the model, $T_{0}$; the total cloudiness, $C$; the relative humidity computed from the dew point temperature at $2 \mathrm{~m}, r h$; the $10 \mathrm{~m}$ wind velocity amplitude, $\left|\boldsymbol{V}_{w}\right|$. The different heat bulk expressions for these terms were determined by Castellari et al. (2000) and verified later to give accurate long term heat budgets with ECMWF by Pinardi and Masetti (2000). Briefly, the bulk formulations used are: the Smitsonian astronomical formulas modified by 

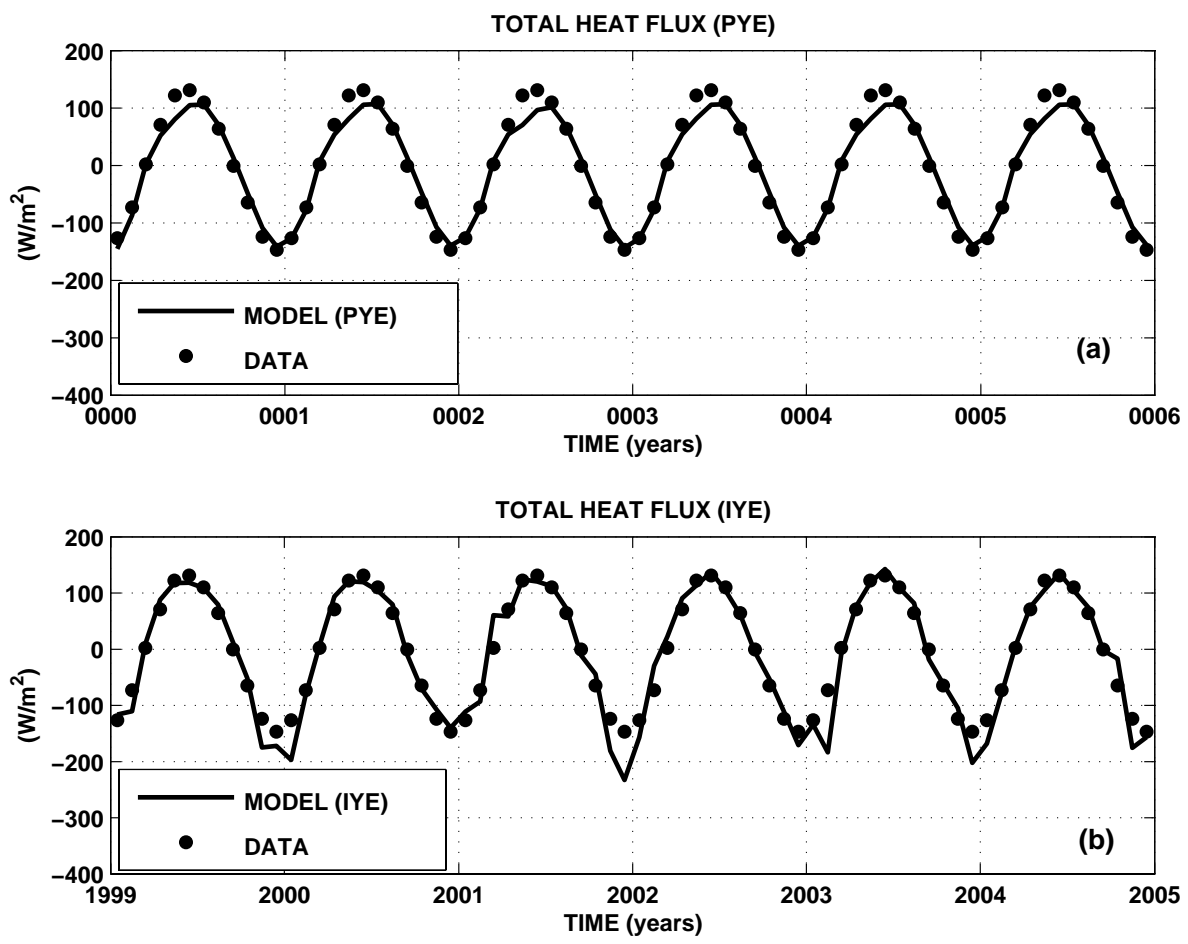

Fig. 6. Comparison between the total heat flux $\left(\mathrm{W} / \mathrm{m}^{2}\right)$ computed from the model experiments and the NCEP NCAR reanalysis. Both model and data are monthly mean. Panel (a) shows the results for the six years of the perpetual year forcing experiment. Panel (b) shows the results for the interannual forcing experiment from January 1999 to December 2004.

Reed (1977) for $Q_{s}$; the Bignami et al. (1995) for $Q_{B}$; the Gill (1982) for $L E$ and Kondo (1975) for $H$ fluxes.

The model initial condition for IYE are the climatological fields of temperature and salinity from MEDATLAS and zero velocity.

\section{Model results and comparison with data}

Both experiments have been studied, intercompared and compared with observations. One of the key indices of the circulation is the value of the kinetic energy over the Mediterranean basin. The Atlantic box circulation is neglected because we consider the Atlantic box as a parameterization of large scale effects. Figure 5 shows the values of Kinetic Energy for (PYE), panel a) and (IYE), panel b). The values increase during the first months of simulation in both experiments. The Kinetic Energy reaches a more or less stable value in (PYE) after the third year of integration. The values for experiment (IYE) seem to reach a statistically flat trend after the first two years of its run. As expected, the values of Kinetic Energy are higher and have more variability in (IYE) than in (PYE), due to the fact that (IYE) is forced by the atmospheric large scale interannual variability (PYE).

The first two years of (IYE) could be considered as the time necessary for the model spin-up; in the following sec- tions we therefore show only the results from 1999. The sixth year of perpetual simulation will be considered as the reference year for (PYE).

The model results were first compared with independent data sets for the heat and wind stress forcing. Figure 6 shows a time series of the total heat flux, described in Eq. (24) and computed as basin mean for (PYE) and (IYE) over a time period mean of one month. The model values are compared with the NCEP/NCAR re-analysis values (Kalnay et al., 1996). (PYE), panel a), does have lower values than NCEP/NCAR during the summer but it reproduces the seasonal cycle rather faithfully. (IYE), panel b), on the contrary, reproduces the summer well, and shows a large interannual variability in the winter fluxes, as was expected. Overall, we may say that the model is forced by consistent heat fluxes in both the (PYE) and (IYE) experiments.

The monthly wind stress mean over the basin is now analyzed together with the monthly mean wind stress curl.

Figure 7 shows the wind stress and wind stress curl computed for both experiment (PYE) and (IYE). The values of wind stress of (PYE) have been compared with the wind stress computed from the NCEP/NCAR data (panel a). The major difference between (PYE) and NCEP/NCAR data is during summer. NCEP/NCAR shows a summer minimum whilst (PYE) reaches a secondary maximum during the same period. Examining the wind stress pattern (not shown) we 

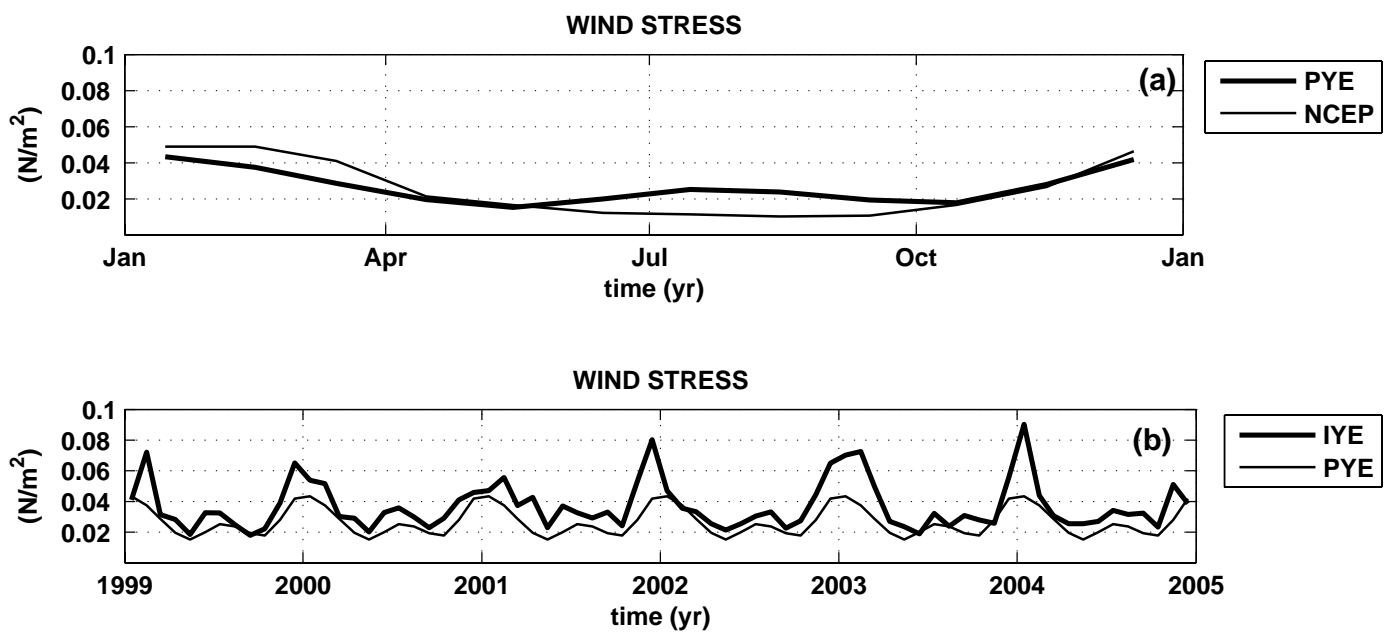

WIND STRESS CURL

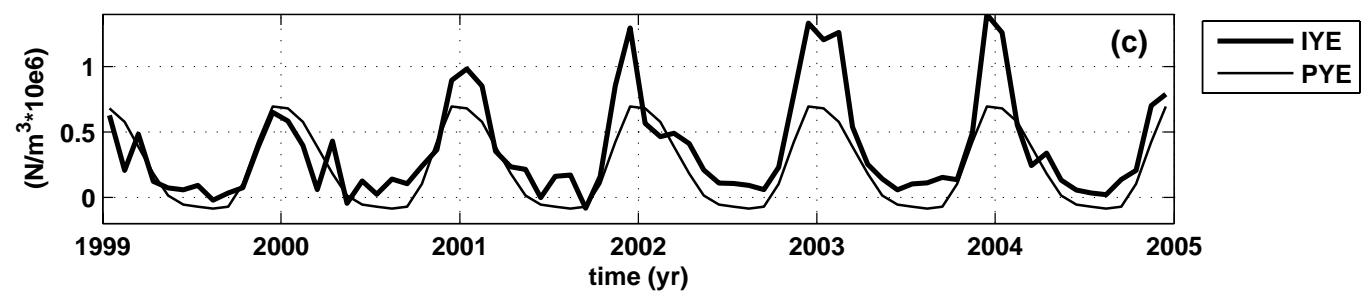

Fig. 7. Wind stress $\left(N / \mathrm{m}^{2}\right)$ and wind stress curl $\left(N / \mathrm{m}^{3} \times 10^{6}\right)$ from model simulations and NCEP-NCAR data as mean over the Mediterranean Basin. Panel (a): climatological monthly mean wind stress from NCEP-NCAR (thin line) and monthly mean from the sixth year of the perpetual forcing experiment (thick line). Panel (b): wind stress from model simulation from January 1999 to December 2004 (thick line) and the perpetual year simulation values (thin line). Panel (c): wind stress curl from the model simulations from January 1999 to December 2004 (thick line) and the perpetual year experiment (thin line).

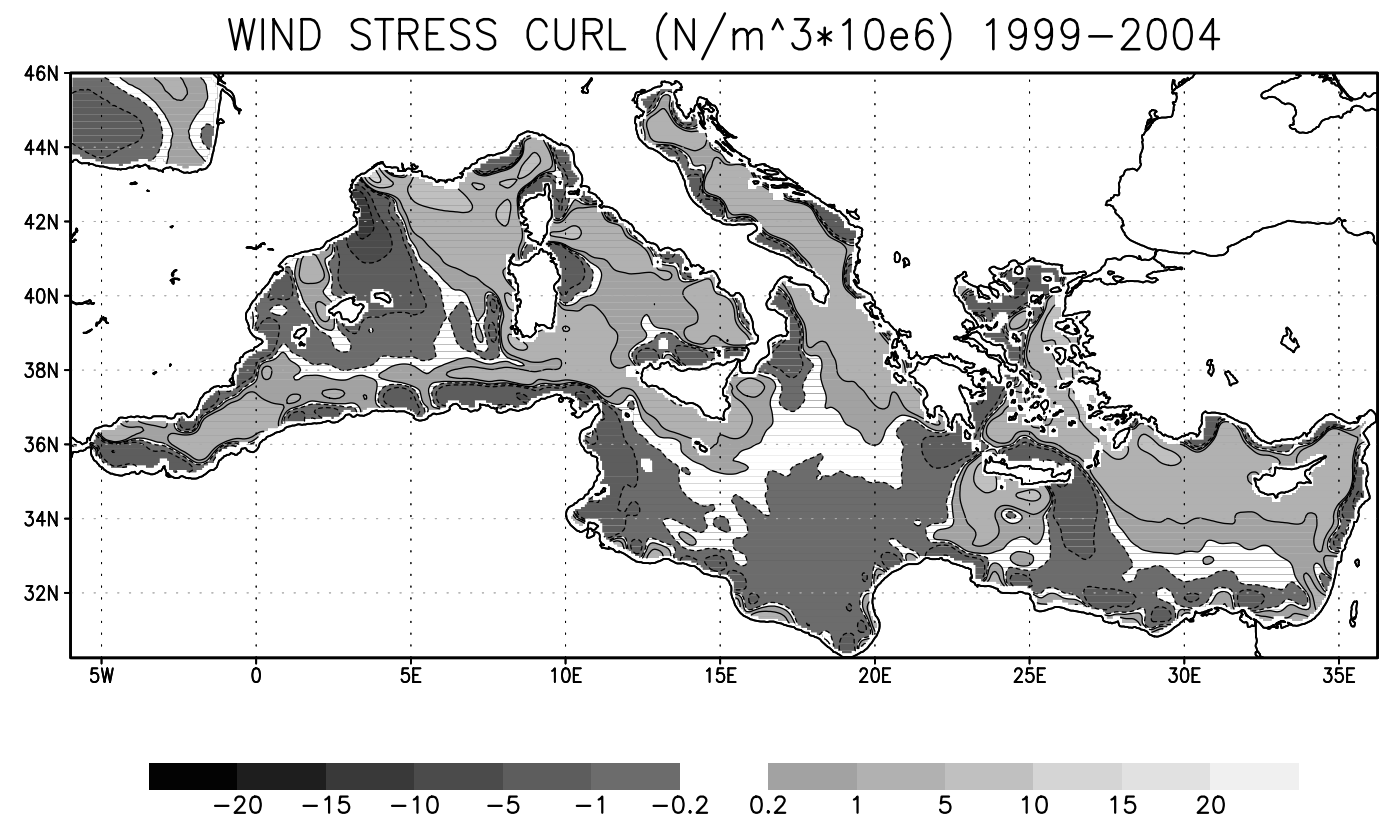

Fig. 8. Map of wind stress curl computed as average from the model experiments over the years 1999-2004. 


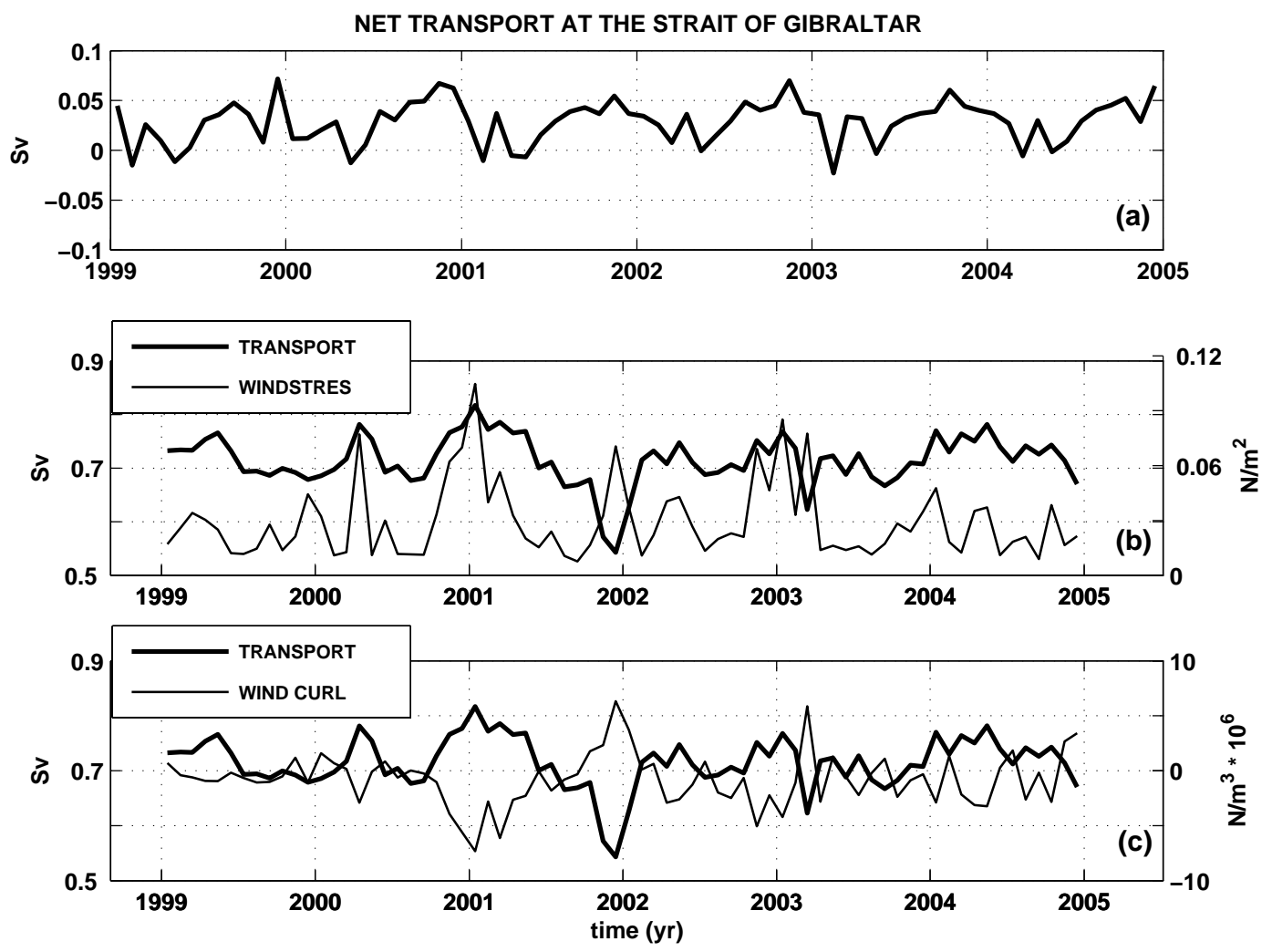

Fig. 9. Baroclinic transport (Sv) at the Strait of Gibraltar and wind stress and wind stress curl as mean in the Alboran Sea. Panel (a): net transport (eastward minus westward) at the Strait of Gibraltar over the period January 1999-December 2004. Panel (b): eastward transport at Gibraltar (thick line) and wind stress (thin line) as mean over the Alboran Sea $\left(6^{\circ} \mathrm{W}-1^{\circ} \mathrm{W}\right)$ for the same period. Panel (c): eastward transport at Gibraltar (thick line) and wind stress curl (thin line) as mean over the Alboran Sea $\left(6^{\circ} \mathrm{W}-1^{\circ} \mathrm{W}\right)$ for the same period.

note that the large amplitude meridional winds characterizing the summer regimes over the Eastern Mediterranean are very weak in the NCEP/NCAR climatology, and this could explain the difference. The (PYE) forcing, calculated from ECMWF re-analysis (Korres et al., 2000), have the large amplitude signal of the Etesian winds, however.

Panel b) represents the wind stress from (IYE) over the years 1999-2004 compared with (PYE). Both curves show a large seasonal signal but (IYE) shows a higher amplitude, especially during winter. The first three years of (IYE) are characterized by lower values of wind stress with respect to the final three years. Panel c) shows the wind stress curl from (PYE) and (IYE). The values of the wind stress curl are characterized by a seasonal signal and are mainly positive for the Mediterranean basin (as the basin is forced to have a cyclonic vorticity input). The years 2002, 2003 and 2004 have the largest wind stress curl values. In conclusion, we may approximately say that the atmospheric forcing variability in (PYE) and (IYE) reproduces the well-known patterns and is consistent with an independent data set.

Figure 8 shows a map of the wind stress curl computed as mean over (IYE) from 1999 to 2004. The curl is positive over a vast area of the northern part of the basin, with the exception of the western part of the Gulf of Lion. The curl is mainly negative in the southern part of the Mediterranean, however. This is the well-known pattern of the wind stress curl over the Mediterranean (Pinardi and Mosetti, 2000; Demirov and Pinardi, 2002) that has been advocated in the past as the main cause for the cyclonic character of the basin-scale general circulation and anticyclonic circulation prevailing in the southern and south-eastern parts of the basin.

The mass transport at the main straits of the Mediterranean Sea is another important index of the basin scale circulation, and is also connected to deep and intermediate water formation processes in the basin. The two main straits are the Strait of Gibraltar that connects the Mediterranean sea with the Atlantic Ocean and the Sicily Strait, subdividing the Mediterranean Sea into the western and eastern parts.

The transport at the Gibraltar Strait is characterized by the inflow of the surface Atlantic water, corresponding to low salinity and the outflow of salty Mediterranean waters below $150 \mathrm{~m}$ approximately. The Strait of Gibraltar is $13 \mathrm{~km}$ wide at its narrowest part and has a maximum depth of $350 \mathrm{~m}$. It is difficult for a model with a horizontal resolution of approximately $7 \mathrm{~km}$ to simulate the exchange at this strait well (in 

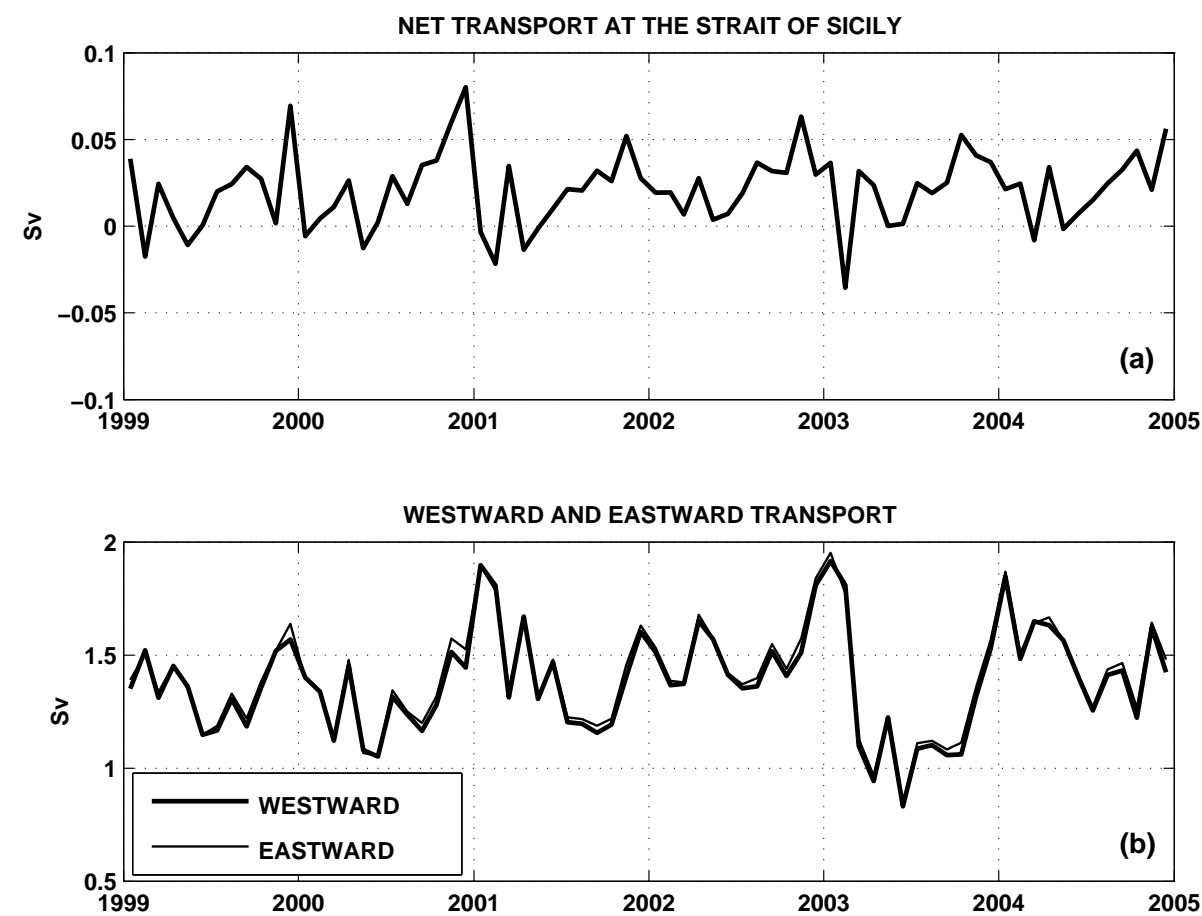

Fig. 10. Baroclinic transport at the Strait of Sicily (Sv). Panel (a): net transport for the period January 1999-December 2004 from the interannual experiment. Panel (b): eastward (thin line) and westward (thick line) transport component at the Strait of Sicily from January 1999-December 2004.

the model the strait at its narrowest part is represented by 2 grid points). As explained in Sect. 2, special parameterizations have been developed for this area. With a free-surface model, the net transport is different from zero and the inflow should be bigger than the outflow to balance the net water loss at the sea surface. The eastward and westward transport at the Strait of Gibraltar it is computed through a section at $6^{\circ} \mathrm{W}$. The net transport is the difference between these two components. It is shown in Fig. 9, and seasonal cycle is large and reaches maximum values in autumn. In March of some years, the net transport (panel a) may be negative, but the average values over the year are always positive. It is clear that the net transport has a large seasonal cycle with interannual fluctuations superimposed. The eastward and westward transport at the Strait of Gibraltar have approximately the same fluctuation with no clear evidence of a seasonal signal. The variability of the eastward and westward transport is strictly related to the wind stress, as has already been pointed out in other works (Beranger et al., 2005). The wind stress and wind stress curl monthly mean have been computed over the area between $6^{\circ} \mathrm{W}$ and $1^{\circ} \mathrm{W}$ of longitude, corresponding to the Alboran Sea, for the years 1999-2004. Panels b) and c) of Fig. 9 show the value of the wind stress and the wind stress curl respectively superimposed with the eastward transport. It is evident that the variability of the transport is more strongly correlated with the wind stress curl than with the wind stress intensity. When the curl is strongly negative (positive) the transport is high (low). When the curl is negative (positive) the vorticity is anticyclonic (cyclonic) and the wind direction should be mainly eastward (westward). January 2001 has a high transport and the curl is negative, whilst in December 2001 the transport reaches its minimum value and the curl is strongly positive, but in both cases (panel b) the wind stress is high. The time series of panel c) of Fig. 9 shows clearly how the correlation between the transport and the wind stress curl is well respected during all the period of study.

Figure 10 shows the transports at the Sicily Strait: panel a) the net transport and panel b) the eastward and westward component. From panel b) it is clear that the westward and eastward values have larger values than at Gibraltar, confirming the results from Pinardi et al. (1997) with lower resolution models. The net transport, panel a), has values and shape comparable to the net transport at Gibraltar. The westward and eastward components have a high variability with high values of transport in winter that are lower in summer. The time variability is in good agreement with observations made over the years 1999-2001 (Beranger et al., 2004), and the values of the maximum transport simulated by the model also have values comparable with those observed. For example, the maximum at the beginning of 2001 evidenced from observation is well reproduced by the model simulation. The model seems, however, to over-estimate the minimum values of the transport, which are around $0.7 \mathrm{~Sv}$ during the period 

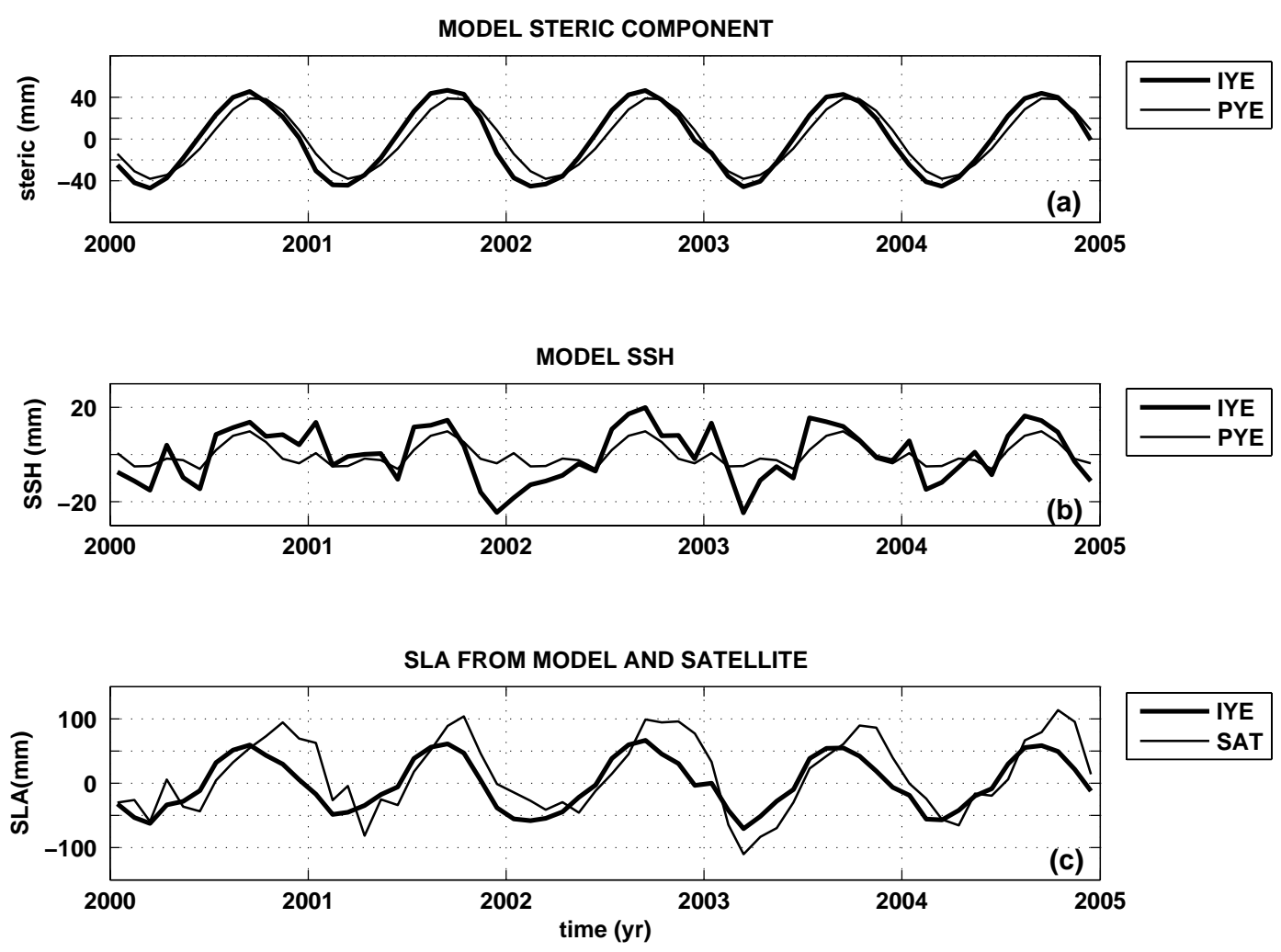

Fig. 11. Sea Level anaomaly mean over the Mediterranean basin for the period January 1999-December 2004. The unit of measure is mm. Panel (a): steric componet variability computed for the perpetual year simulation (thin line) and the interannual year experiment (thick line). Panel (b): dynamic topography computed from the model sea surface high for the perpetual year experiment (thin line) and the interannual year (thick line). Panel (c): Sea level anomaly from January 1999 to December 2004 as mean over the Mediterranean basin from satellite monthly values (thin line) and model simulation for the same period (thick line).

of 1999-2001 from the observation and never less then $1 \mathrm{~Sv}$ from the model simulation for the same period.

Another way to assess the interannual model performance is to compare the model output with the satellite Sea Level Anomaly (SLA) time series. The model computes values of Sea Surface Height (SSH) without considering the steric effect because it solves the incompressible continuity equation described in Eq. (4). Mass changes do not create a threedimensional divergence and thus the steric effect is a diagnostic quantity for our model. The steric component was then computed from the density field of the model and added to the SSH. Figure 11, panel a), shows the values of the steric component for both (PYE) and (IYE). The values are very similar for the two experiments and the seasonal cycle is clear with higher values during the summer. The values oscillate between $-40 \mathrm{~mm}$ in winter and $+40 \mathrm{~mm}$ in summer. The area average values of SSH from the model are also shown in panel b), and in this case the difference between (PYE) and (IYE) is evident. The signal ranges between $-25 \mathrm{~mm}$ and $+20 \mathrm{~mm}$ in (IYE) and $-5 \mathrm{~mm}$ and $+10 \mathrm{~mm}$ for (PYE) showing that the sea level interannual signal is half of the steric seasonal signal in the Mediterranean Sea. In other words sea level variations induced by large scale circulation changes produced by wind, water and heat fluxes over the Mediterranean Sea have half the amplitude of the steric seasonal effects.

The SLA from the model has been defined as the sum of the steric component and the model SSH where every year its mean value has been subtracted. This time mean is equivalent to subtracting the mean sea level or mean dynamic topography of the model. This is done because the satellite altimetry values also have such value subtracted. Panel c) of Fig. 11 represents the comparison between (IYE) and the satellite data. (IYE) reproduces the seasonal variability and part of the interannual variability well but it is missing the high values during the late summer-autumn period.

Before discussing this mismatch, we would like to show the comparison of the model simulation with in-situ temperature and salinity profiles.

XBT and ARGO vertical profiles were collected over years 2003 and 2004 within the MFSTEP framework. The rms error between data and model have been computed at different depths (30, 150 and $300 \mathrm{~m}$ ) and then averaged over each month. Panel a) of Fig. 12 shows the rms for temperature from XBT. The rms has values with a high variability, especially at the surface, and it could be due to the scarcity 

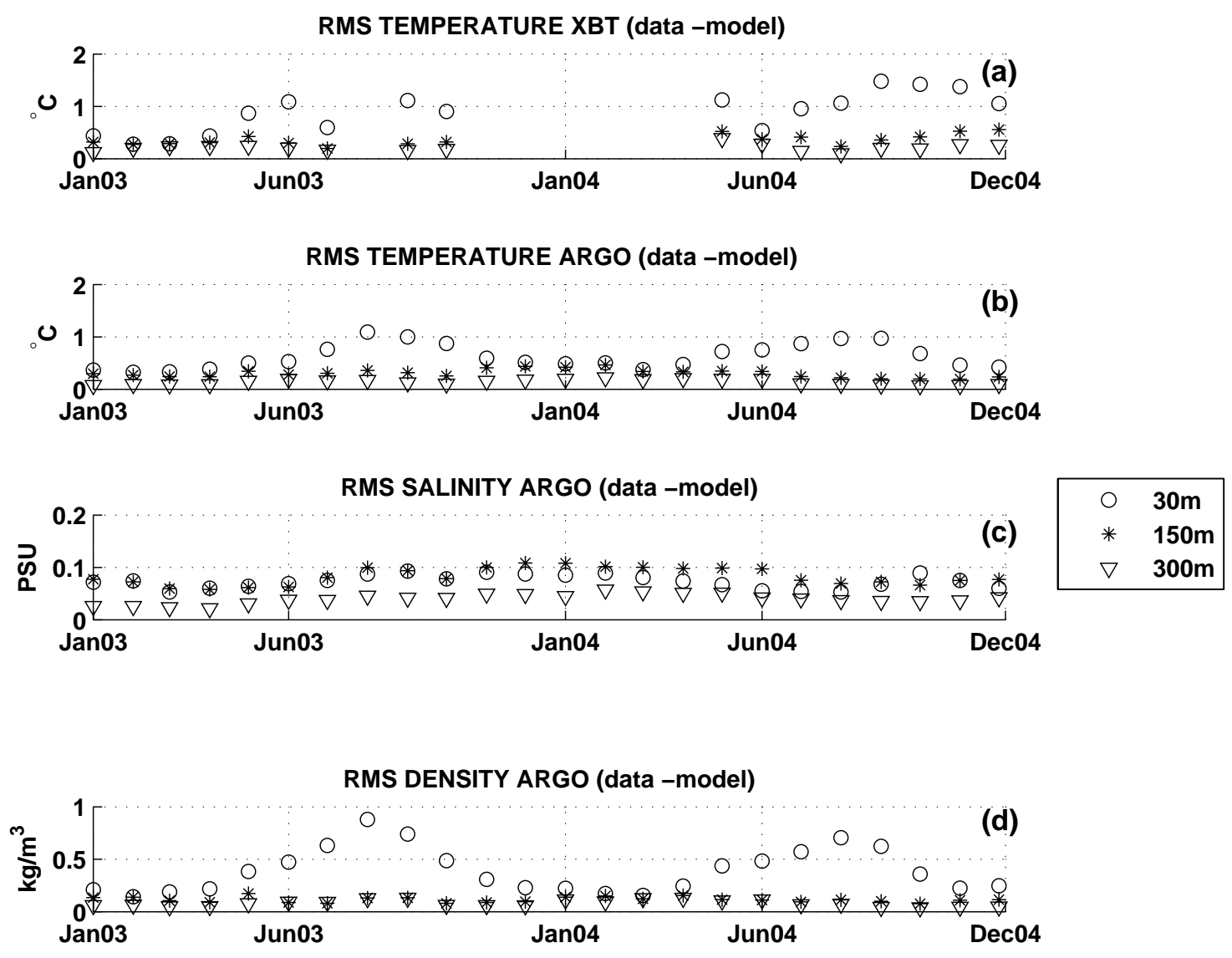

Fig. 12. Rms error between data and model for year 2003 and 2004 at 30, 150 and $300 \mathrm{~m}$ depth. Panel (a): XBTs-model temperature rms $\left({ }^{\circ} \mathrm{C}\right)$; panel (b): ARGOS-model temperature rms $\left({ }^{\circ} \mathrm{C}\right)$; panel (c) ARGOs-model salinity(psu); panel (d) ARGOs-model density rms $\left(\mathrm{kg} / \mathrm{m}^{3}\right)$.

in space of the data. The rms with the ARGO (Panel b), on the other hand, shows values lower than $0.5^{\circ} \mathrm{C}$, except in the summer, when the error is much larger at the depth of $30 \mathrm{~m}$. This could be due to the misplacement of the seasonal thermocline in the model simulation. This situation is present also in panel c), which shows the rms for the salinity (Dobricic et al., 2007). The rms at $30 \mathrm{~m}$ is generally about $0.08 \mathrm{psu}$ in September of both 2003 and 2004, and could reach a value of 1.6-1.8 psu. At 150 and $300 \mathrm{~m}$ the rms does not have this fluctuation. The rms at $150 \mathrm{~m}$ has values close to $0.08 \mathrm{psu}$ with oscillation that could reach values of 1.2 psu or decrease down to $0.02 \mathrm{psu}$. At $300 \mathrm{~m}$ the rms is about $0.04 \mathrm{psu}$. Panel d) shows the rms of the density computed from temperature and salinity data from ARGO versus model. These values are well consistent with the results of salinity and temperature discussed above.

We can now try to understand the differences in late summer-autumn in Fig. 11. This is due mainly to two factors:

1. the wrong water flux during summer, which lacks the high evaporative fluxes during late summer and autumn;
2. the upper mixed layer physics, which does not correctly reproduce the relatively deep, hot and salty mixed layer during the summer-autumn period.

This interpretation is supported by the results of both Fig. 11 and Fig. 12, which show that the model has large model errors in the upper seasonal thermocline.

Figure 13 represents the velocity field at $30 \mathrm{~m}$ as averaged over 1999-2004. The model is able to reproduce the main circulation patterns of the Mediterranean Sea as described in the literature (Millot et al., 2005; Pinardi et al., 2004; Robinson et al., 1002).

\section{Conclusions}

The experiments described in this study confirm that the high-resolution free-surface model implemented in the first phase of the MFSTEP project has a good capability in reproducing the ocean dynamic of the Mediterranean Sea. This study shows that model results are in agreement with the data and observations, even though some parameterizations of the 


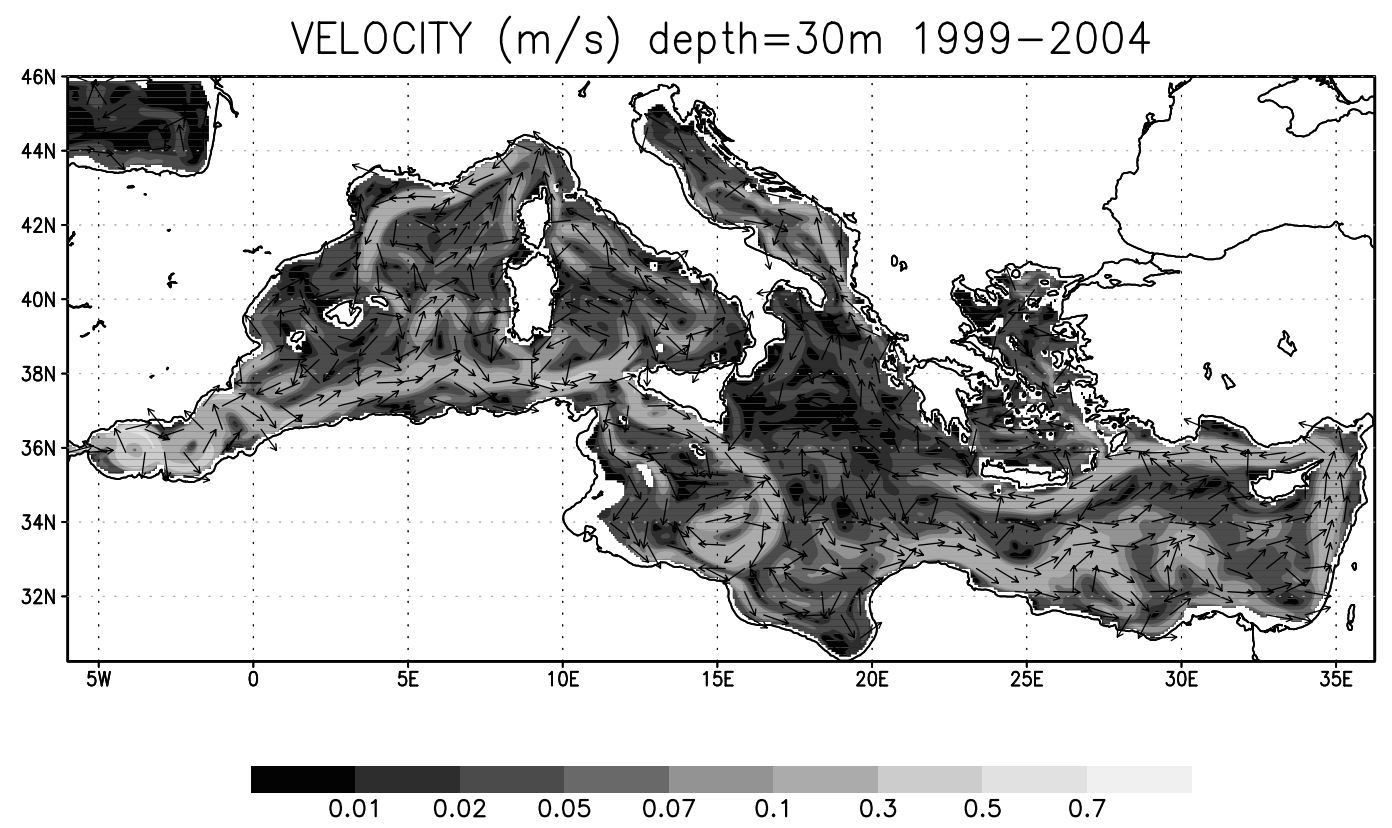

Fig. 13. Map of the circulation over the Mediterranean basin at $30 \mathrm{~m}$ computed as mean over the model simulation from 1999 to 2004.

model should be improved. This is the case of the water flux, which should be more realistic, and, as pointed out in Sect. 4, also of the model's capability of the model to reproduce the hot and salty mixed layer during the summer-autumn period correctly. The computation of an SLA and the possibility to compare it to the satellite data is an important improvement with respect to the previous lower-resolution and rigid lid models implemented over the Mediterranean sea.

\section{Appendix A}

\section{A1 Bathymetry and coastline}

The Digital Bathymetric Data Base-Variable Resolution has been used to make the MFS1671 coastlines and bathymetry. DBDB-1 at 1' resolution has been used for the Mediterranean basin, whilst for the Atlantic DBDB-2 and DBDB-5 have been used. The bathymetry file has been manually corrected along the Croatian coast by a comparison with detailed nautical charts. The bathymetry has been interpolated on the model horizontal and vertical grid and manually checked for isolated grid point, islands and straits and passages.

\section{A2 Vertical level distribution}

The distribution of the unevenly distributed vertical levels should satisfy the criteria of consistency and accuracy of the numerical scheme (Treguier et al., 1996). The vertical distribution of the levels is computed in OPA by a function that has a nearly uniform vertical level distribution at the ocean top and bottom with a smooth hyperbolic tangent transition in between. Several level distributions have been computed in order to find the one that reproduce the vertical shape of temperature and salinity profiles for the region best. Particular attention has been paid to the intermediate layer resolution where the water masses are characterized by only $0.5^{\circ} \mathrm{C}$ anomalies in the western Mediterranean.

\section{A3 Temperature and salinity monthly mean climatology}

MEDATLAS monthly mean climatology (MEDAR/MEDATLAS Group, 2002) and WOA98 (Levitus, 1998) gridded climatologies have been used for the Mediterranean Sea and the Atlantic Ocean respectively. The merging between the two climatologies has been done in a region on the western side of the Strait of Gibraltar.

\section{A4 Wind stress and heat flux perpetual year climatology}

The wind stress monthly mean climatology has been performed with two different data set, one for the Atlantic and one for the Mediterranean. The monthly mean wind stress for the Mediterranean Sea has been computed by Korres and Lascaratos (2003) using the ECMWF re-analysis fields for the period 1979-1993. The monthly mean climatology from Hellerman and Rosenstein (1983) has been used for the Atlantic box. A weight function depending on distance in longitude has been used to merge the two monthly data sets, and the data have then been interpolated with a spline on the numerical ocean model grid.

The perpetual year climatology for the heat flux covers only the Mediterranean and for the Atlantic only the relaxation to climatological temperature is used (see text). The 
heat fluxes have been computed by Korres and Lascaratos (2003) using the COADS cloud cover data set for the period from 1980 to 1988 and the Reynolds SST.

Edited by: E. J. M. Delhez

\section{References}

Beranger, K., Mortier, L., Gasparini, G. P., Gervasio, L., Astraldi, M., and Crepon, M.: The dynamics of the Sicily Strait: a comprehensive study from observations and model, Deep Sea Res. II, 51, 411-440, 2004.

Beranger, K., Mortier, L., and Crepon, M.: Seasonal variability of water transport through the Straits of Gibraltar, Sicily and Corsica, derived from a high-resolution model of the Mediterranean circulation, Prog. Ocean., 66, 341-364, 2005.

Castellari, S., Pinardi, N. and Leaman, K.: A model study of air-sea interactions in the Mediterranean Sea, J. Mar. Syst., 18, 89-114, 2000.

Demirov, E., Pinardi, N., Fratianni, C., Tonani, M., Giacomelli, L., and De Mey, P.: Assimilation scheme of the Mediterranean Forecasting System: operational implementation, Ann. Geophys., 21, 189-194, 2003, http://www.ann-geophys.net/21/189/2003/.

Demirov, E. and PInardi, N.: The simulation of the Mediterranean Sea circulation from 1979 to 1993. Part I: The interannual variability, J. Mar Syst., 33-34, 23-50, 2002.

Dobricic, S., Pinardi, N., Adani, M., Tonani, M., Fratianni, C., Bonazzi, A., Fernandez, V.: Daily oceanographic analyses by the Mediterranean basin scale assimilation system, Ocean Sci., 3, 149-157, 2007, http://www.ocean-sci.net/3/149/2007/.

Hellerman, S. and Rosestein, M.: Normal monthly wind stress over the world ocean with error estimates, J. Phys. Oceanogr., 13, 1093-1104, 1983.

Kalnay E., Kanamitsu, M., Kistler, R., Collins, W., Deeven, D., Gandin, L., Iredell, M., Saha, S., White, G., Wollen, J., Zhu, Y., Chelliah, M., Ebisuzaki, W., Higgins, W., Janoviak, J., Mo, K. C., Ropelewsy, C., Wang, J., Leetma Reynold, R., Jenne, R., and Joseph, D.: The NCEP/NCAR 40-Years Reanalysis Project, B. Am. Meteorol. Soc., 77, 437-471, 1996.

Korres, G., Pinardi, N., and Lascaratos, A.: The ocean response to low frequency interannual atmospheric variability in the Mediterranean Sea: Part I: Sensitivity experiments and energy analysis, J. Climate, 13, 705-731, 2000.

Korres, G. and Lascaratos, A.: A one-way nested, eddy resolving model of the Aegean and Levantine basins: Implementation and climatological runs, Ann. Geophys., 21, 1, 205-220, 2003.
Madec, G., Delecluse, P., Imbard, M., and Levy, C.: OPA8.1 Ocean general Circulation Model reference manual. Note du Pole de modelisazion, Institut Pierre-Simon Laplace (IPSL), France, 11, 1998.

MEDAR/MEDATLAS Group: MEDAR/MEDATLAS 19982001 Mediterranean and Black Sea database of temperature, salinity and bio-chemical parameters and climatological atlas (4CDroms), European Commission Marine Science and Technology Programme, and internet server http://www.ifremer. fr/sismer/program/medarIFREMER/TMSI/IDM/SISMER Ed., Centre de Brest), 2002.

Millot, C. and Tapier-Letage, I.: Circulation in the Mediterranean Sea. Handbook of Environmental Chemistry, vol.5, Part K: 2966, D=I 10.1007/b 107143, Springer-Verlag Berlin Heidelberg, 2005.

Pinardi, N., Allen, I., Demirov, E., De Mey, P., Korres, G., Lascaratos, A., Le Traon, P. Y., Maillard, C., Manzella, G., and Tziavos, C.: The Mediterranean ocean Forecasting System : first phase of implementation (1998-2001), Ann. Geophys., 21, 320, 2003, http://www.ann-geophys.net/21/3/2003/.

Pinardi, N. and Masetti, E.: Variability of the large scale general circulation of the Mediterranean Sea from observations and modelling: a review, Palaeo, 158, 153-174, 2000.

Pinardi, N., Korres, G., Lascaratos, A., Roussenov, V., and Stanev, E.: Numerical simulation of the interannual variability of the Mediterranean Sea upper ocean circulation, Geophys. Res. Lett., 24, 425-428, 1997.

Pinardi, N., Arneri, E., Crise, A., Ravaioli, M., and Zavatarelli, M.: The physical and ecological structure and variability of shelf areas in the Mediterranean Sea, "The Sea", Vol. 14, Chapter 32, 2006.

Reed, R. K.: On estimating insolation over ocean, J. Phys. Oceanogr., 17, 854-871, 1977.

Robinson, A., Malanotte-Rizzoli, P., Hecht, A., Nichelato, A., Roether, W., Theocharis, A., Unluata, U., Pinardi, N., and the POEM Group: General circulation of the eastern Mediterranean, Earth Sci. Rev., 285-309, 1992.

Roullet, G. and Madec, G.: Salt conservation, free surface, and varying levels: a new formulation for ocean general circulation models, J. Geophys. Res., 105(C10), 23 927-23 942, 2000.

Sannino, G., Bargagli, A., and Artale, V.: Numerical modeling of the semidiurnal tide exchange through the Starti of Gibraltar, J. Geophys. Res., 107, C5011, doi:10.1029/2001JC000929, 2002.

Treguier, A. M., Dukowicz, J. K., and Bryan, K.: Properties of nonuniform grid used in general circulation models, J. Geophys. Res., 101(C9), 20 877-20 881, 1996. 